\title{
Práticas ambientais adotadas por microempreendedores da rede de oficinas automotivas no município de Corrente/PI
}

O município de Corrente/PI, conta com oficinas mecânicas que prestam serviços de conserto e manutenção de automóveis a fim de estender a sua vida útil, atividades como essas geram elementos poluentes e consequentes impactos negativos ao ambiente e à saúde pública. Em vista disso, o presente estudo propôsse a verificar a existência de práticas ambientais adotadas pelos microempreendedores do setor de oficina mecânica de reparo automotivo no município de Corrente/PI. Para tanto foram utilizados os métodos de pesquisa bibliográfica, como suporte inicial para posterior aplicação de um questionário estruturado e semiestruturado, composto por onze perguntas. Dezoito oficinas de reparo automotivo participaram da pesquisa, dentre os resultados: $94,4 \%$ adotam práticas ambientais; $55,6 \%$ dos respondentes não possuem conhecimento sobre a legislação ambiental; $88,8 \%$ não adotam um Sistema de Gestão Ambiental. Considerando os objetivos propostos, pôde-se verificar a existência de práticas ambientais nas oficinas ainda que voltadas principalmente para a organização e limpeza local, o que já evidencia um bom começo na busca pela adequação dessas oficinas, apresentando os resultados satisfatórios que podem ser obtidos através das boas práticas ambientais, apontando ainda, formas de reduzir a geração dos resíduos e valorar os resíduos recicláveis.

Palavras-chave: Gerenciamento de resíduos; Gestão organizacional; Responsabilidade socioambiental.

\section{Enviromnmental practices adopted by microentrepreneurs in the network of automotive workshops in the county of Corrente/PI}

\begin{abstract}
The county of Corrente/PI, counts on mechanical workshops that provide repair and maintenance of cars in order to extend their useful life, activities such as pollutants and consequent negative impacts on the environment and the environment public health. In view of this, the present study aimed to verify the existence of environmental practices adopted by micro entrepreneurs in the sector of mechanical workshop of automotive repair in the county of Corrente/PI. For this purpose the bibliographic research methods were used, as an initial support to final application of a structured and semi-structured questionnaire, composed of eleven questions. Eighteen automotive repair workshops participated in the survey, among results: $94.4 \%$ adopt environmental practices; $55.6 \%$ of respondents do not have knowledge about environmental legislation; $88.8 \%$ do not adopt a Management System Environmental. Considering the proposed objectives, it was possible to verify the existence of environmental practices in the workshops, although they focus mainly on the organization and local cleaning, which already shows a good start in the search for the adequacy, showing satisfactory results that can be obtained through good environmental practices, as well as ways to reduce the generation of waste and give value recyclable waste.
\end{abstract}

Keywords: Waste management; Organizational management; Social environmental responsibility.

Topic: Desenvolvimento, Sustentabilidade e Meio Ambiente

Reviewed anonymously in the process of blind peer.
Received: 10/08/2018

Approved: 24/09/2018

Priscila Souza Lustosa

Instituto Federal do Piauí, Brasil

http://lattes.cnpq.br/0846480279538871

http://orcid.org/0000-0002-0058-3459

priscilalustosa22@gmail.com

Israel Lobato Rocha (it)

Instituto Federal do Piauí, Brasil

http://lattes.cnpq.br/6518724518793037

http://orcid.org/0000-0002-4496-9935

israel.lobato@ifpi.edu.br

Bruna de Freitas Iwata (D)

Instituto Federal do Piauí, Brasil

http://lattes.cnpq.br/3036032785449787

http://orcid.org/0000-0002-6465-9731

iwata@ifpi.edu.br

Referencing this:

LUSTOSA, P. S.; ROCHA, I. L.; IWATA, B. F.. Práticas ambientais adotadas por microempreendedores da rede de oficinas automotivas no município de Corrente/PI. Revista Ibero Americana de Ciências Ambientais, v.9, n.7, p.257-272, 2018. DOI:

http://doi.org/10.6008/CBPC2179-6858.2018.007.0024 


\section{INTRODUÇÃO}

Os diferentes tipos de empreendimentos geram em seus processos, impactos positivos ou negativos, diretamente relacionados ao modelo gerencial da organização, visto que os impactos ocorrem a partir de um aspecto ambiental oriundo da atividade executada. Nesse sentido, é importante que haja compatibilização ambiental entre a adoção de práticas dentro de todo o fluxograma de funcionamento da organização desde processos de usos da matéria prima até o descarte dos resíduos gerados.

Bernardo et al. (2012) destacam que as práticas ambientais são definidas como estratégias adotadas com o propósito de diminuir ou evitar os impactos ambientais, como o consumo de recursos naturais e poluição do solo, ar, água e sonora. Segundo o SEBRAE (2018), o fim do incentivo do governo para aquisição do veículo novo ocorrido em 2012 e 2013 e a recente crise econômica vem ocasionando o aumento do tempo de permanência do veículo usado pelo proprietário (aproximadamente 9 anos). Dessa forma, conforme os prazos de garantia de manutenção nas concessionárias vencem (média de três anos), cresce a demanda por reparação nas oficinas mecânicas.

Em se tratando dos processos envolvidos no gerenciamento de resíduos, o tratamento e destinação são imprescindíveis como medidas de atenuação dos efeitos causados ao meio ambiente e à saúde pública, uma vez que o tratamento e destinação incluem procedimentos destinados a reduzir o potencial poluidor do resíduo, em observância à legislação ambiental vigente. Para tanto, vê-se como necessário incorporar a educação ambiental no ambiente empresarial explicitando a importância da responsabilidade individual e coletiva para, então, aplicar esse aprendizado em práticas sustentáveis.

Conforme os autores El Tugoz et al. (2017), comportamentos ambientalmente corretos devem ser aprendidos na prática. A educação tem na ação concreta um de seus principais alicerces, envolvendo atitudes e comportamentos que, repetindo-se e transformando-se no dia a dia, poderão vir a consolidar-se como prática socialmente aceita.

Considerando a necessidade de ações ou práticas que agregam responsabilidade socioambiental como empreendimento gerador de impactos, esse estudo propôs-se a verificar a existência de práticas ambientais adotadas pelos microempreendedores do setor de oficina mecânica de reparo automotivo no município de Corrente/PI.

\section{REVISÃO TEÓRICA}

O crescimento populacional e sua relação com o aumento na geração de resíduos sólidos e consequentes impactos ambientais

Conforme afirma Campos (2012), em 2009, a massa coletada de resíduos sólidos domiciliares e públicos variou de 0,77 kg.habitante ${ }^{-1} \cdot$ dia $^{-1}$ a $1,19 \mathrm{~kg} \cdot$ habitante $^{-1} \cdot \mathrm{dia}^{-1}$, e a média foi de 0,96 kg.habitante ${ }^{-1} \cdot$ dia $^{-}$ 1. Quanto à evolução da geração per capita de resíduos sólidos no Brasil, Campos (2012) ressaltou que a média per capita dessa geração de resíduos correspondeu a $359 \mathrm{~kg}$.habitante $\mathrm{h}^{-1}$.ano ${ }^{-1}$. Em termos percentuais, a geração per capita de resíduos sólidos tem crescido mais do que a população e o Produto Interno Bruto - 
PIB tem crescido menos do que a geração de resíduos sólidos. Nesse mesmo ano, houve uma inflexão no crescimento do PIB enquanto a geração total de resíduos continuou aumentando.

Já em 2016, a ABRELPE (Associação Brasileira de Empresas de Limpeza Pública e Resíduos Especiais, 2017) lançou o “Panorama dos Resíduos Sólidos no Brasil 2016", o qual informava que o brasileiro produziu, em 2016, 1,040 kg de lixo por dia. O dado seria animador se toda a gestão de coleta, destinação e recursos aplicados no seguimento de limpeza também tivessem progredido. A primeira pesquisa reflete que o aumento na geração de resíduos sólidos envolve fatores que estão além do crescimento populacional, que estão diretamente ligados aos padrões culturais, renda e hábitos de consumo da sociedade.

Algumas hipóteses que podem estar contribuindo em maior ou menor escala com o aumento da geração per capita dos resíduos sólidos: aumento do emprego e elevação da massa salarial; redução do número de pessoas por domicílio e da composição familiar; maior participação da mulher no mercado de trabalho; fluxo de retorno da migração nordestina para o Sul de volta ao Nordeste, estimulando novos hábitos de consumo; maior facilidade na obtenção de crédito para o consumo; não cobrança pelos serviços de coleta e manejo dos resíduos sólidos aos munícipes; estímulo frenético ao consumo pelos veículos de comunicação; uso indiscriminado de produtos descartáveis. (CAMPOS, 2012)

Com relação às regiões brasileiras, Campos (2012) apresentou o ranking da crescente geração per capita de resíduos sólidos, no qual a região Sul aparece com $0,81 \mathrm{~kg}$.habitante ${ }^{-1} \cdot \mathrm{dia}^{-1}$; a região Sudeste com 0,88; Nordeste com 1,03; Norte com 1,15 e Centro-oeste com 1,47 kg.habitante ${ }^{-1}$.dia-1 ${ }^{-1}$. Godecke et al. (2012) frisam que os aspectos econômicos e culturais se associam à questão demográfica para acelerar o ritmo da deterioração dos recursos ambientais. A essa afirmação acrescenta-se o que Querino et al. (2016) enfatizam em relação ao consumo dos recursos naturais de $30 \%$ a mais do que o planeta pode naturalmente repor sendo necessário reduzir a desigualdade no acesso a esses recursos. Os autores Godecke et al. (2012) ainda destacam a relação entre a quantidade de resíduos sólidos produzidos pelas populações não só com o nível de riqueza, refletido na capacidade econômica para consumir, mas também com os valores e hábitos de vida, determinantes do grau de disposição para a realização do consumo.

Conforme Godecke et al. (2012), dados da WWF - World Wide Fund for Nature (Fundo Mundial para a Vida Selvagem e Natureza), em 2010, evidenciam que nos últimos 40 anos estima-se que o planeta tenha perdido $30 \%$ da sua biodiversidade, com maior impacto nos países tropicais, onde a perda atingiu $60 \%$ da fauna e flora originais. Aliás, impactos na saúde e qualidade de vida da sociedade também podem ser evidenciados devido à precariedade na gestão dos resíduos sólidos urbanos, consoante o que versa o art. 1ำ da Resolução CONAMA no 001 (BRASIL, 1986), a qual considera impacto ambiental qualquer alteração das propriedades físicas, químicas e biológicas do meio ambiente, causada por qualquer forma de matéria ou energia resultante das atividades humanas que, direta ou indiretamente, afetam a saúde, a segurança e o bem-estar da população; as atividades sociais e econômicas; a biota; as condições estéticas e sanitárias do meio ambiente e a qualidade dos recursos ambientais.

Em contrapartida à definição supramencionada, Sánchez (2013) conceitua impacto ambiental como sendo: "[...] alteração da qualidade ambiental que resulta da modificação de processos naturais ou sociais desencadeados por ação humana. Impacto ambiental é, claramente, o resultado de uma ação humana, que é a sua causa". O impacto ambiental altera as propriedades do meio físico, biótico e antrópico, podendo 
apresentar conotação benéfica ou adversa. Os resíduos sólidos mal gerenciados, em suma, podem poluir ou contaminar o solo ou um corpo hídrico, podem atrair vetores de patógenos, assim como causar poluição visual. Com a finalidade de reduzir tais alterações, articulam-se estratégias particulares a cada situaçãoproblema e se propõe medidas mitigadoras com foco nos impactos negativos e nas particularidades que cada ambiente e atividade possuem.

\section{Gerenciamento de resíduos sólidos}

Os resíduos sólidos são materiais ou substâncias inservíveis para determinado fim e que foram descartados para então receberem a destinação ambientalmente adequada. A Política Nacional de Resíduos Sólidos - Lei no 12.305 (BRASIL, 2010) define, no art. 3, inciso X, gerenciamento de resíduos sólidos como o conjunto de ações exercidas, direta ou indiretamente, nas etapas de coleta, transporte, transbordo, tratamento e destinação final ambientalmente adequada dos resíduos sólidos e disposição final ambientalmente adequada dos rejeitos, de acordo com o plano municipal de gestão integrada de resíduos sólidos ou o plano de gerenciamento dos resíduos sólidos.

Segundo Gerhardt et al. (2014) as normas da ISO 14000-2004 conceituam a gestão ambiental como um conjunto de medidas e procedimentos bem definidos que, se adequadamente aplicados, permitem reduzir e controlar os impactos introduzidos por um empreendimento sobre o meio ambiente. Já para Martins et al. (2016), a gestão ambiental corresponde ao conjunto de diretrizes e atividades administrativas e operacionais realizadas pela empresa para abordar problemas ambientais decorrentes da sua atuação ou para evitar que eles ocorram no futuro.

As atividades desenvolvidas por oficinas mecânicas, relacionadas à reparação de veículos automotores, geram diferentes tipos de resíduos sólidos e efluentes que precisam de tratamento adequado para que seu descarte não cause danos ao meio ambiente e à saúde pública (GERHARDT et al., 2014).

Gerhardt et al. (2014) destacam ainda que as principais atividades como: troca de óleo lubrificante, fluidos de arrefecimento e hidráulicos, troca e limpeza de peças, retífica de motores, injeção eletrônica, suspensão, freios, regulagem de motor, alinhamento e balanceamento, entre outras desenvolvidas por oficinas mecânicas, geram grande quantidade de resíduos sólidos, entre os principais encontram-se peças usadas, pneus, latarias, flanela, estopas sujas, papelão e embalagens de peças e de óleos lubrificantes.

Os autores supracitados acrescentam que a separação na fonte é uma estratégia fundamental para garantir a correta destinação dos resíduos. A contaminação de qualquer resíduo com óleo lubrificante automotivo usado pode inviabilizar técnica ou financeiramente o gerenciamento. A segregação contribui para um menor volume de resíduos perigosos a ser tratado ou disposto em Aterros de Resíduos Perigosos. Após a separação na fonte, os resíduos devem ser adequadamente armazenados, aguardando o encaminhamento ao tratamento ou a disposição final.

Todos os resíduos provenientes das atividades realizadas nas oficinas mecânicas devem ser segregados e acondicionados em observância ao prescrito na Resolução CONAMA no 275 (BRASIL, 2001), na qual estão estabelecidos os códigos de cores para os diferentes tipos de resíduos e a identificação dos 
respectivos coletores. $\mathrm{O}$ acondicionamento deve ser feito em recipientes compatíveis com a quantidade diária de resíduos gerados, estes recipientes podem ser: tambores, contêineres, tanques ou a granel.

Segundo a Norma Brasileira - NBR 12235 (ABNT, 1992) resíduos ou substâncias que, ao se misturarem, provoquem efeitos indesejáveis, como fogo, liberação de gases tóxicos ou ainda que facilitem a lixiviação de substâncias tóxicas, não devem ser colocados em contato. É importante que os resíduos sejam armazenados de tal forma que não possibilite a sua alteração.

A Associação Brasileira de Normas Técnicas - ABNT, NBR 11174:1990 regulamenta sobre o armazenamento de resíduos classe II - não inertes, os quais não devem ser armazenados juntamente com resíduos classe I (perigosos), em face da possibilidade da mistura resultante ser caracterizada como resíduo perigoso. Caso haja contato entre resíduos de classes diferentes, o resíduo não perigoso pode ser contaminado e tornar-se perigoso, consequentemente o gerenciamento será comprometido e os custos para sua destinação serão maiores. Dessa forma, Gerhardt et al. (2014) propõem que as áreas destinadas à armazenagem dos resíduos devem ser cobertas, a fim de evitar a ação da chuva e de outras intempéries, garantindo condições de segurança, até que os resíduos sejam transportados para a disposição final.

De acordo com a Resolução CONAMA 362 (BRASIL, 2005), as empresas que fazem o transporte de óleo lubrificante usado devem estar cadastradas no Órgão Regulador da Indústria de Petróleo (Agência Nacional do Petróleo, Gás Natural e Biocombustíveis - ANP) e licenciadas pelo órgão ambiental competente. Veículos coletores devem atender às normas da sinalização de segurança previstas no decreto 96.044 de 18 de maio de 1988 da Agência Nacional de Transportes Terrestres (ANTT).

A última etapa para o correto gerenciamento de resíduos nas oficinas é a destinação final destes, sendo de grande importância na logística de manejo dos resíduos, uma vez que depois do gerenciamento adequado desses materiais no empreendimento, o mesmo deve ser depositado em locais que garantam a preservação do meio ambiente, ou ainda podem, dependendo do material, receber algum tratamento, como a reciclagem, incineração ou compostagem. $O$ tratamento dos resíduos procede visando a sua reutilização ou pelo menos sua inertização, de forma não prejudicar o meio ambiente e a saúde da população. (LACOURT, 2012, citado por GERHARDT et al., 2014)

\section{Relação entre sustentabilidade e gestão organizacional}

O termo sustentabilidade pode ser definido como ações que envolvem a utilização responsável dos recursos naturais de modo a garantir a existência destes para usufruto das gerações vindouras. Estudos apresentam a sustentabilidade apoiada pelo tripé: ambiental, social e econômico, aspectos estes que se inter-relacionam de maneira que atinjam equilíbrio. Esses aspectos são também conhecidos como tripple bottom line sugerido por Elkington (1994), abordados no Brasil como o Tripé da Sustentabilidade.

Eckert et al. (2015) apresentam a sustentabilidade como o princípio de assegurar que as ações que são tomadas no presente não limitarão as opções econômicas, sociais e ambientais das gerações futuras. Dessa forma, o desenvolvimento sustentável incorpora três princípios, relacionados a integridade ambiental, equidade social e prosperidade econômica, onde o desempenho de um princípio reflete diretamente sobre o desempenho dos outros dois. 
Corroborando com o exposto anteriormente, Justen et al. (2012) consideram que a dimensão econômica abrange tanto a atividade econômica formal quanto a economia informal, encampando toda a atividade produtiva. A dimensão ambiental ou ecológica preocupa-se com o impacto das atividades empresariais sobre o meio ambiente. Sendo assim, implica, além do monitoramento, a análise do ciclo de vida do produto e a administração integrada da cadeia de produção. A dimensão social evidencia os aspectos sociais relacionados às qualidades dos seres humanos, como suas habilidades, dedicação e experiências, nos âmbitos interno e externo da organização.

Almeida (2002) destaca que a sustentabilidade exige uma postura preventiva, que identifique tudo que um empreendimento pode causar de positivo - para ser maximizado - e de negativo - para ser minimizado. Os avanços tecnológicos que o homem foi capaz de obter tornaram cada vez mais curto o tempo para que um impacto sobre o meio ambiente e sobre a sociedade seja plenamente sentido. A reparação, porém, nem sempre pode ser acelerada. Além disso, alguns processos de degradação atingem tais níveis que não são mais passíveis de recuperação. Esta pode até ser viável tecnicamente, mas não economicamente.

As micro, pequenas e médias empresas possuem significativa importância para o desenvolvimento econômico de um município, devido sua representatividade ser maior. $\mathrm{O}$ que também não as reserva de adotarem práticas ambientais que contribuam para a melhoria do ambiente local. Conforme esclarecem Martins et al. (2016), embora, individualmente, cada atividade das pequenas e médias empresas (PMEs) represente apenas uma micro parcela da poluição global, estima-se que o impacto coletivo delas no meio ambiente seja substancial, podendo, inclusive, superar a soma do impacto ambiental das grandes empresas.

Logo, essa temática deve estar inserida em todo e qualquer hábito do cotidiano, como uma forma de gestão do comportamento humano, seja ele dentro ou fora da organização. Seguindo essa linha de pensamento, Hepper et al. (2016) afirmam que a investigação teórica e empírica muitas vezes aponta para uma relação positiva entre a sustentabilidade empresarial e desempenho organizacional, mas que as tentativas de conceituar a natureza multidimensional das práticas de sustentabilidade são raras na literatura atual.

Assim, Morais et al. (2014) compartilham a ideia de que o reposicionamento da proteção ambiental da esfera da função produtiva para se tornar componente da função administrativa, determina uma nova interação entre empresa e meio ambiente, na qual os fatores ambientais são agregados às diretrizes - metas, políticas e estratégias - e a proteção ambiental passa a integrar os objetivos organizacionais.

Dessa maneira a gerência da organização pode incorporar práticas ambientais à sua gestão empresarial como ferramenta de desenvolvimento econômico, melhoria no ambiente de trabalho e qualidade de vida, conforme afirmam Eckert et al. (2015) quando definem a gestão ambiental como o processo de alocação dos recursos naturais de modo a otimizar a sua utilização no atendimento de necessidades humanas básicas, se possível, por um período indeterminado e com o mínimo de impactos negativos ao meio ambiente.

Martins et al. (2016) afirmam que, considerada como nova função empresarial, a gestão ambiental possibilita que as empresas administrem adequadamente suas relações com o meio ambiente ao avaliarem 
e corrigirem danos ambientais do presente ou evitarem problemas futuros, e ao integrarem articuladamente todos os setores da empresa quanto aos imperativos ambientais.

O gerenciamento eficaz de resíduos sólidos proporciona benefícios econômicos uma vez que permite que os materiais recicláveis que possuam valor comercial sejam vendidos nos mercados específicos para cada tipo material. Assim, o resultado financeiro da operação, medido pela diferença entre a receita gerada pela da venda dos materiais e a despesa com movimentação e destinação dos mesmos representa uma fonte de geração de receita muitas vezes bastante significativa para as empresas. (STEPHANOU, 2013)

Contudo, Souza (2013) enfatiza que a mudança na conduta das empresas em direção a posições mais sustentáveis não é apenas uma questão de consciência moral ou econômica dos empresários. As empresas operam sob as contingências dos seus contextos particulares, de modo que os empresários não têm total liberdade sobre as suas ações, e a possibilidade ou não das ações ambientais trazerem benefícios econômicos é uma particularidade de cada contexto. Neste sentido, sem entender as razões que as empresas têm para agirem como agem em relação ao meio ambiente, pouco poderemos influenciar suas ações em direção à sustentabilidade ambiental. Ou seja, trata-se de entender as estratégias ambientais das empresas em seu próprio contexto. É o que afirmam Martins et al. (2016):

Atualmente, stakeholders, como clientes, fornecedores, comunidades e governos são os principais responsáveis por pressões para a implementação de práticas empresariais que proporcionem melhores condições ambientais para o planeta. Empresas de grande porte, além de estarem mais preparadas para atender a esses requisitos, também adotam as ferramentas de gestão ambiental a partir de uma visão estratégica, buscando alcançar, simultaneamente, um melhor desempenho ambiental e econômico. No entanto, as pequenas e médias empresas (PMEs), devido às suas especificidades de gestão, não podem fazer uso dos mesmos mecanismos utilizados pelas grandes organizações para minimizar os impactos ambientais causados por suas atividades.

Conforme Barretto (2012), do total de 3.912 empresários entrevistados, somente $46 \%$ das micro e pequenas empresas brasileiras acreditam que a questão do meio ambiente pode gerar ganhos financeiros a seus negócios. Salienta Eckert et al. (2015) que as principais dificuldades das empresas na gestão ambiental se concentram nas tecnologias de processamento de resíduos, nos custos operacionais e de manutenção dos sistemas de reaproveitamento, de reciclagem e de tratamento. Além disso, mas em menor intensidade, a legislação, a localização da planta, a pouca cultura ambiental e o treinamento.

Assim, Almeida (2002) enfatiza que a prática do desenvolvimento sustentável exige uma combinação equilibrada dos mecanismos de comando-e-controle, autorregulação e instrumentos de mercado. Comandoe-controle são as regulamentações governamentais, com padrões de desempenho definidos para tecnologias e produtos, emissão de efluentes, disposição de rejeitos e assim por diante. Autorregulação significa as iniciativas das empresas para regularem a si mesmas, através do estabelecimento de padrões, monitoramento e metas de redução de poluição. Um exemplo de autorregulação é a adesão a sistemas de certificação como as normas ISO. Instrumentos econômicos são os utilizados pelos governos para influir no mercado. Compreendem impostos e encargos sobre poluição, preços diferenciais para estimular/desestimular produtos ambientalmente adequados/inadequados, entre outros. 


\section{Práticas ambientais em estabelecimentos de reparação automotiva e aspectos legais}

A preservação ambiental tem sido uns dos temas mais discutidos globalmente, e com o passar dos anos foram sendo elaboradas leis, resoluções e normas que pudessem ser aplicadas nas diferentes situações de condutas nocivas ao meio ambiente. A Constituição Federal brasileira (BRASIL, 1988) estabelece em seu capítulo $\mathrm{VI}$, art. 225 , sob os fundamentos do desenvolvimento sustentável, que todos têm direito ao meio ambiente equilibrado, que proporcione sadia qualidade de vida, incumbindo ainda aos usuários dos recursos naturais, a proteção e preservação desse meio ambiente. Para a efetivação do que está proposto nesse capítulo da CF, leis e resoluções precisam ser aplicadas de acordo com a finalidade para as quais foram elaboradas. É o caso da construção de empreendimentos sujeitos ao licenciamento ambiental, cujas atividades utilizam recursos ambientais, e que são potencialmente poluidores e que causem qualquer tipo de degradação ao meio ambiente.

A conscientização ecológica no ramo automotivo partiu de montadoras até atingir fornecedores, fabricantes e os estabelecimentos de manutenção e reparo de veículos. Nesse sentido, o trabalho de separação de resíduos e descarte correto de peças numa oficina mecânica começa com a conscientização dos seus colaboradores. Os mecânicos precisam desenvolver a cultura da preservação do meio ambiente, começando com atitudes simples, e a partir daí fazer desse exercício uma constante no seu local de trabalho e até mesmo em casa. O método de separação de água e óleo, por exemplo, já é recomendado pelo Instituto de Qualidade Automotiva (IQA), mas passará a ser condicionante para certificação em uma auditoria.

Em consonância ao que traz a ABNT, NBR 10004 (BRASIL, 2004), norma que classifica os resíduos sólidos quanto aos seus riscos potenciais ao meio ambiente e à saúde pública, os resíduos são classificados em: resíduos Classe I - perigosos; resíduos Classe II - não perigosos. Estes em: resíduos Classe II A - não inertes e resíduos Classe II B - inertes.

Baseados na ABNT, NBR 10004:2004, Gerhardt et al. (2014) explicam que os resíduos Classe I Perigosos, são todos os resíduos que possuem propriedades físicas, químicas ou infectocontagiosas as quais podem causar riscos à saúde pública e/ou riscos ou danos ao meio ambiente, quando gerenciado de forma inadequada. Para que um resíduo seja apontado e considerado perigoso, ele deve estar contido nos anexos A ou B da NBR 10004 ou apresentar uma ou mais das seguintes características: inflamabilidade, corrosividade, reatividade, toxicidade e patogenicidade. Os resíduos Classe II - Não Perigosos são divididos em inertes e não inertes, sendo considerados resíduos Classe II-A (Não Inertes), os resíduos que apresentam propriedades como biodegradabilidade, combustibilidade ou solubilidade em água e não se enquadram na classificação acima, Classe - I Perigosos e nem na Classe II B- Inertes. Já os resíduos Classe II-B (Inertes), são todos os resíduos que quando amostrados de uma forma representativa, segundo a ABNT NBR 10007:2004, e submetidos a um contato dinâmico e estático com água destilada ou deionizada, à temperatura ambiente, conforme ABNT NBR 10006:2004, não tiverem nenhum de seus constituintes solubilizados a concentrações superiores aos padrões de potabilidade de água, excetuando-se aspecto, cor, turbidez, dureza e sabor. A partir da distribuição dos resíduos de acordo com suas características baseados na norma mencionada, é 
possível identificar o enquadramento dos resíduos gerados nas oficinas mecânicas, bem como os aspectos e impactos relacionados a esses resíduos.

Dentre os impactos ambientais causados pelas oficinas e atividades econômicas em geral, a geração de resíduos sólidos está presente, em maior ou menor escala, o que torna o assunto relevante no tocante à aplicação de práticas responsáveis voltadas à preservação do meio ambiente. Os serviços prestados pelas oficinas mecânicas representam uma atividade com certo grau poluidor, ainda assim, não passível de licenciamento, como pode ser averiguado na Resolução CONAMA no 237 (BRASIL, 1997) a qual elenca as atividades ou empreendimentos sujeitos ao processo de licenciamento ambiental. O que também não as exime de adotar práticas voltadas à mitigação dos impactos por elas gerados.

O art. 54, § 20, inciso V da Lei de Crimes Ambientais (BRASIL, 1998) estabelece que lançamento de resíduos sólidos, líquidos ou gasosos, ou detritos, óleos ou substâncias oleosas, em desacordo com as exigências estabelecidas em leis ou regulamentos incorre em pena de reclusão, de um a cinco anos. Dessa forma, é importante que as oficinas mecânicas atendam ao previsto na Resolução do CONAMA no 362 (BRASIL, 2005), a qual dispõe sobre o recolhimento, coleta e destinação final de óleo lubrificante usado ou contaminado; CONAMA no 416 (BRASIL, 2009) que resolve sobre a prevenção à degradação ambiental causada por pneus inservíveis e sua destinação ambientalmente adequada preconiza no Art. 1으, § 1ํ, que os fabricantes e os importadores de pneus novos, com peso unitário superior a 2,0 kg (dois quilos), ficam obrigados a coletar e dar destinação adequada aos pneus inservíveis existentes no território nacional. Os distribuidores, os revendedores, os destinadores, os consumidores finais de pneus e o Poder Público deverão, em articulação com os fabricantes e importadores, implementar os procedimentos para a coleta dos pneus inservíveis existentes no País, previstos nesta Resolução. A Política Nacional de Resíduos Sólidos - Lei no 12.305 (BRASIL, 2010), também é um importante instrumento norteador que tange ao gerenciamento de resíduos sólidos.

\section{MATERIAIS E MÉTODOS}

\section{Área de estudo}

O estudo foi desenvolvido em 18 oficinas de reparo automotivo no município de Corrente/PI, localizado a 10 26' 30" de latitude Sul e 45 09' 52" de longitude Oeste de Greenwich. Segundo dados do IBGE (2016), o município abrange uma área correspondente a $3.048,477 \mathrm{~km}^{2}$ tendo em seus limites os municípios de Cristalândia, Sebastião Barros, Riacho Frio, Parnaguá, São Gonçalo do Gurgueia, todos no estado do Piauí e Formosa do Rio Preto/BA. De acordo com o Instituto Socioambiental - ISA (2017) o município de Corrente/PI, encontra-se na área de amplitude da Unidade de Conservação Parque Nacional das Nascentes do Rio Parnaíba, a qual ocupa 34.582 ha do município. A figura 1 apresenta os limites geográficos do município, bem como a localização das oficinas mecânicas que participaram do estudo. 


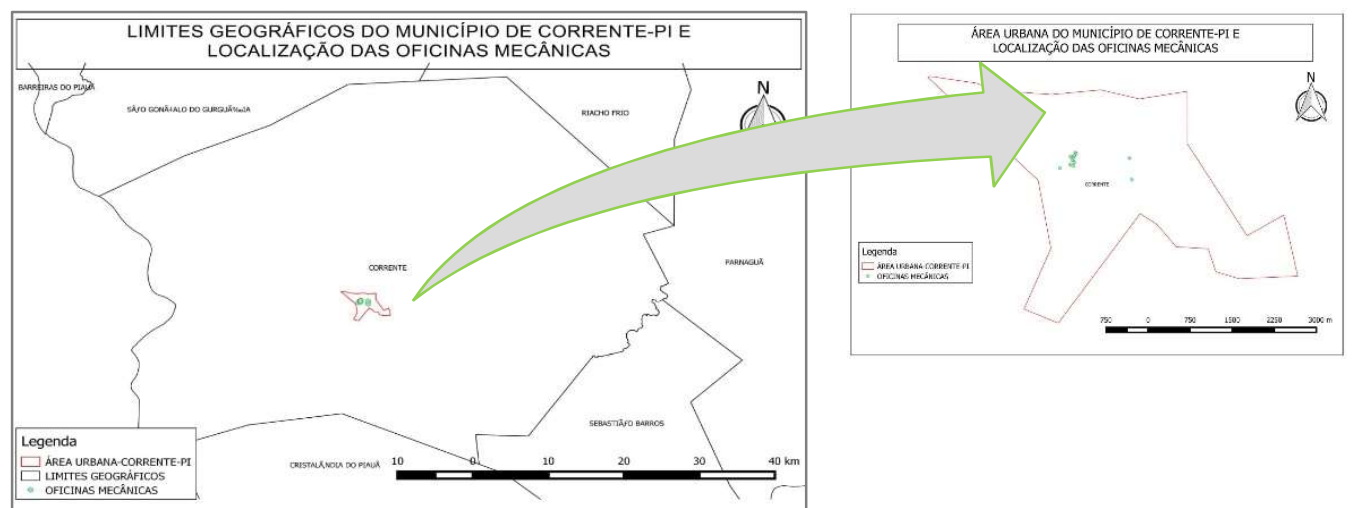

Figura 1: Limites geográficos do município de Corrente/PI, e localização das oficinas que participaram do estudo.

\section{Procedimentos metodológicos}

Para a realização deste estudo foram utilizados os seguintes métodos: pesquisa bibliográfica, através da consulta a artigos científicos, livros, dissertações, revistas científicas e websites, questionário estruturado e semiestruturado para a coleta de dados. Dezoito oficinas participaram do estudo, visto que em alguns estabelecimentos os responsáveis não estavam presentes e/ou não se dispuseram a responder o questionário.

O questionário elaborado (Quadro 1) caracteriza-se em estruturado e semiestruturado composto por onze (11) questionamentos, a partir do qual foram obtidas informações sobre práticas ambientais desenvolvidas pelas empresas, bem como o nível de entendimento - do responsável pelo estabelecimento sobre a importância das questões sustentáveis, em um total de 18 pequenas organizações do setor de oficinas mecânicas automotivas participantes do estudo no município de Corrente/PI.

Quadro 1: Questionário aplicado para diagnóstico das práticas ambientais aplicadas em oficinas mecânicas automotivas no município de Corrente/PI.

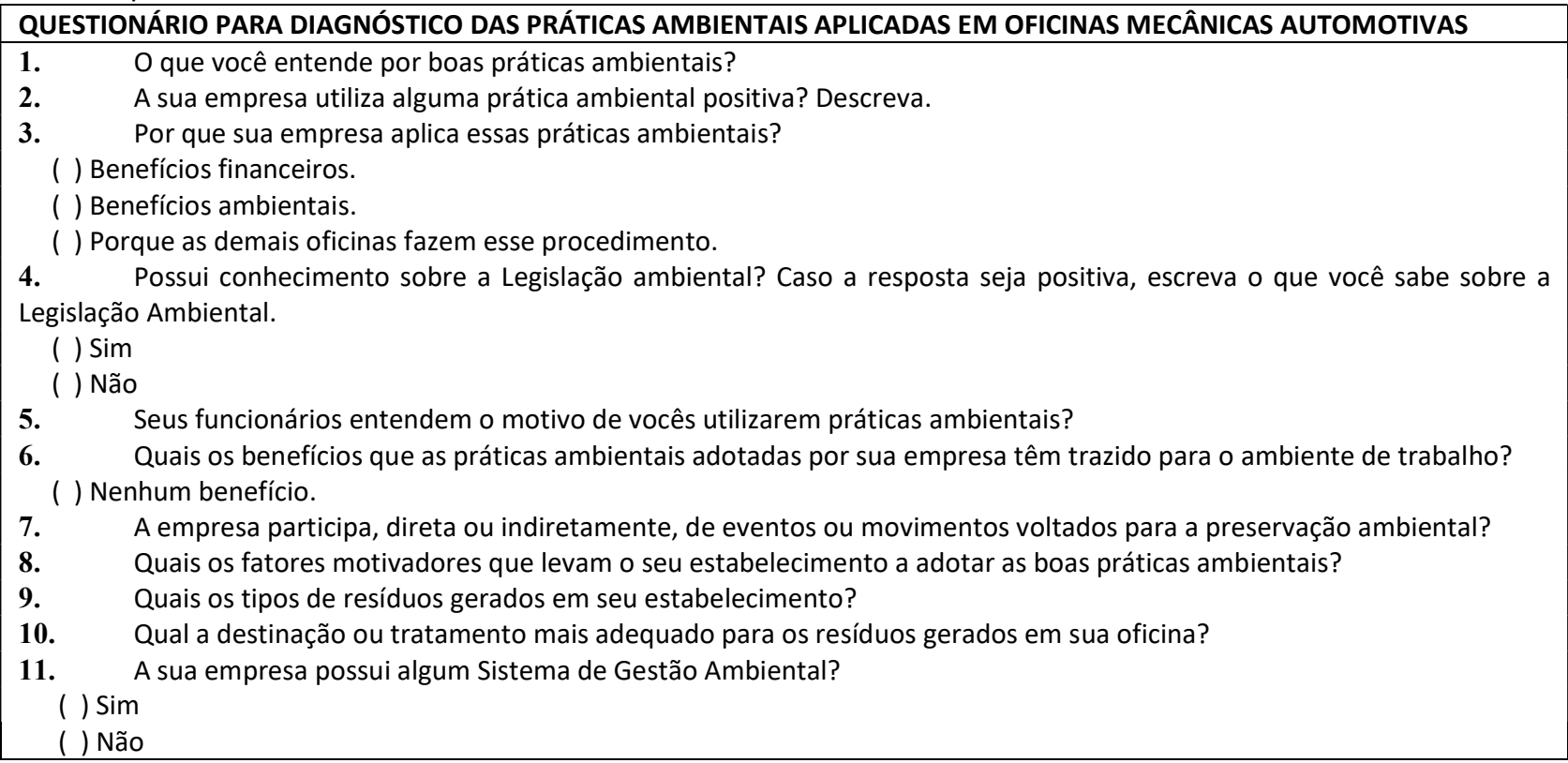

\section{RESULTADOS E DISCUSSÃO}

Com o levantamento de dados verificou-se que $88,9 \%$ dos respondentes afirmaram que práticas ambientais constituem a conservação do ambiente e a manutenção da limpeza na oficina. Os $11,1 \%$ não 
responderam. Com base na definição de Bernardo et al. (2012) as práticas ambientais são definidas como estratégias adotadas com o propósito de diminuir ou evitar os impactos ambientais, a partir da qual pode-se inferir que os responsáveis pelas oficinas entendem, na prática, quais são as ações de preservação do meio ambiente que eles devem ter em seu local de trabalho, visto que as respostas apresentaram-se na forma de exemplos dessas práticas.

Das microempresas que utilizam alguma prática ambiental positiva, aqueles que afirmaram assim proceder foram $94,4 \%$, através da armazenagem dos pneus inservíveis e do óleo usado para venda ou reutilização no próprio estabelecimento, segregação dos resíduos recicláveis, acondicionamento adequado, inclusive em uma das oficinas que trabalha com pintura, o responsável afirmou que o mais breve possível pretende colocar um exaustor na oficina para captar a tinta dispersada.

Ainda dentre os $94,4 \%$ ora citados, outros ainda mencionaram a economia no consumo de água, energia e papel, bem como a devolução de baterias às empresas fornecedoras. 5,6\% afirmou não utilizar prática ambiental porque as demais oficinas não utilizam e porque não tem fiscalização. Logo, percebe-se que mesmo limitadas, algumas práticas ambientais são aplicadas nas oficinas. Toda essa dinâmica contribui para a qualidade ambiental, Gerhardt et al. (2014) corroboram essa importância em definir práticas ambientais que reduzam a geração de resíduos sólidos, mantenham a separação desses na fonte geradora, direcionando-os ao destino adequado, já que esses empreendimentos não são objetos de licenciamento.

No tocante a justificativa para a utilização das práticas ambientais anteriormente descritas, 55,6\% responderam pelos benefícios ambientais; $11 \%$ pelos benefícios ambientais e financeiros; $16,7 \%$ porque as demais oficinas fazem esse procedimento; $16,7 \%$ acrescentaram: pela responsabilidade ambiental; benefícios ambientais e bem-estar; organização e limpeza (Figura 2). Tais justificativas refletem o entendimento dos microempresários quanto à importância de que suas atitudes acarretam consequências capazes de afetar o próprio ambiente de trabalho, o que pode comprometer a qualidade dos serviços prestados. É interessante destacar que duas das oficinas participantes pertencem a proprietários que já trabalharam em empresas que ofereciam treinamentos na área ambiental, a seus funcionários.

Com relação ao conhecimento sobre a Legislação Ambiental, 5,6\% não respondeu; 55,6\% não tem conhecimento; $38,8 \%$ afirmaram sim. Dentre as respostas afirmativas houve a definição de legislação ambiental, outros explicaram com exemplos do cotidiano o conhecimento prático que possuem sobre o assunto (Figura 3). Os que afirmaram ter algum conhecimento sobre o assunto entendem que determinadas ações podem ser lesivas ao meio ambiente, que existem regras de proteção ao meio ambiente e os que não as obedecem podem ser punidos de alguma maneira. Todavia não apontaram conhecer alguma lei específica, por exemplo, a existência de uma Política Nacional de Recursos Hídricos - Lei no 9.433/97 ou a Política Nacional de Resíduos Sólidos - Lei no 12.305/10. 


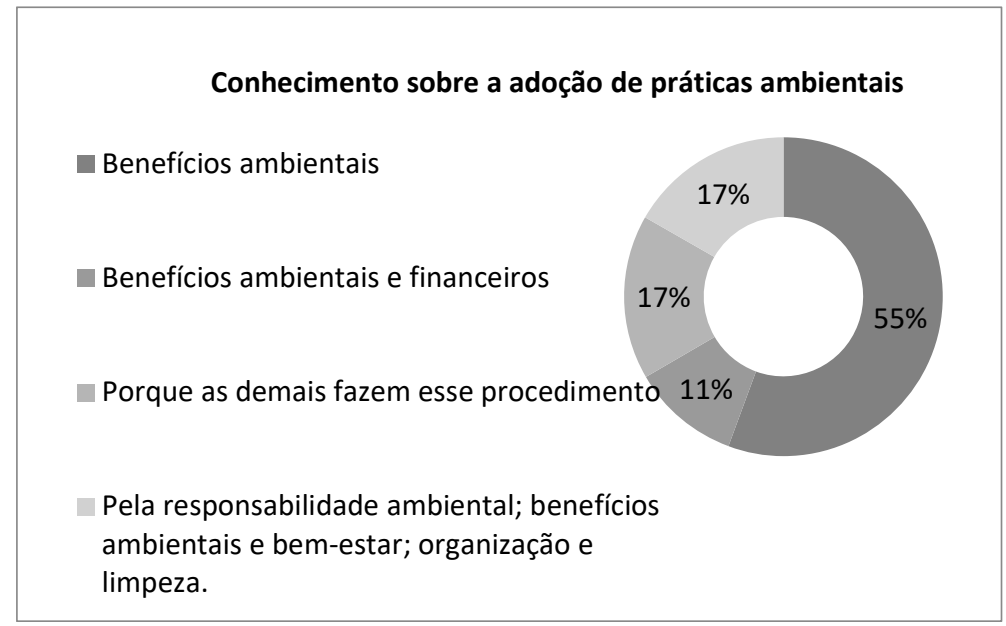

Figura 2: Conhecimento sobre a adoção de práticas ambientais.

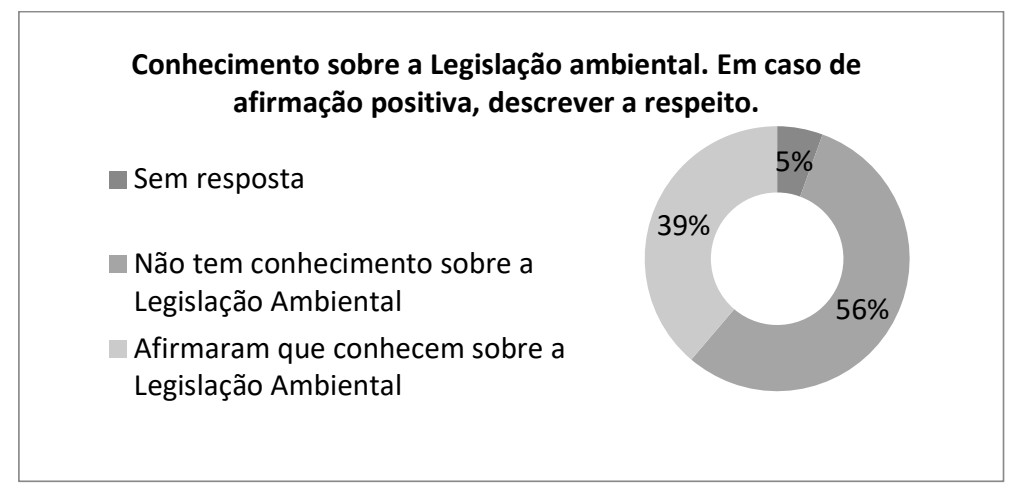

Figura 3: Conhecimento sobre a Legislação ambiental. Em caso de afirmação positiva, descrever a respeito.

No que se refere aos funcionários entenderem o motivo da utilização das práticas ambientais em seu local de trabalho, 66,7\% dos microempresários afirmaram que seus funcionários entendem; 11,1\% não entendem; 11,1\% não possuem funcionários; $11,1 \%$ entendem a questão da limpeza, outro respondeu que em parte, entendem. Nas declarações afirmativas os funcionários são orientados quanto à organização e limpeza da oficina, não foi mencionada a existência de um diálogo semanal ou mensal explicando os motivos de se adotar práticas ambientais. Nas oficinas em que os proprietários já passaram por treinamentos na área ambiental, os funcionários foram orientados por eles. O que indica que a falta de esclarecimento dificulta a aplicação de práticas ambientais.

Em se tratando dos benefícios provenientes das práticas adotadas pelas oficinas, 33,3\% obtiveram um ambiente limpo e organizado; 5,6\% nenhum benefício, já que esse respondente afirmou anteriormente que não utiliza práticas ambientais positivas; $61,1 \%$ foram benefícios atrelados à limpeza e organização interna e externa, à qualidade de vida e de trabalho, redução da poluição e um ambiente saudável, bemestar, redução na conta de energia e água, consciência tranquila, exemplo aos vizinhos para que venham praticar essas ações em benefício ao meio ambiente. Belfi et al. (2014) evidenciaram que a partir das adequações ambientais em um empreendimento, os benefícios são positivos principalmente referentes à redução de custos como em menor consumo de matérias-primas e energia; menor geração de resíduos; diminuição de conflitos com a comunidade e com organismos fiscalizadores, prevenção de acidentes ambientais e dos custos de sua reparação, redução e eliminação de passivos ambientais. 
Quanto à empresa participar, direta ou indiretamente, de eventos ou movimentos de caráter ambiental, 50\% afirmou que não participa; 5,6\% afirmou não ter tido conhecimento sobre tais eventos, caso saiba, participará; em 44,4\% inserem-se aqueles que declararam participar indiretamente, ou seja, através de palestras, cumprindo seu papel de cidadão, foi mencionada a participação das outras filiais, outro comentou ainda que participava quando havia os mutirões de limpeza do rio Corrente (Figura 4). A participação dos dirigentes ou responsáveis pelas oficinas em eventos sobre meio ambiente é um fator importante para o esclarecimento sobre a temática, como certifica Martins et al. (2016) elencando as barreiras à implantação da gestão ambiental em pequenas e médias empresas, nas quais encontram-se descritas a falta de conscientização dos benefícios da gestão ambiental, falta de conhecimento dos dirigentes no campo ambiental, inconsciência de danos ambientais e a falta de informações aos dirigentes.

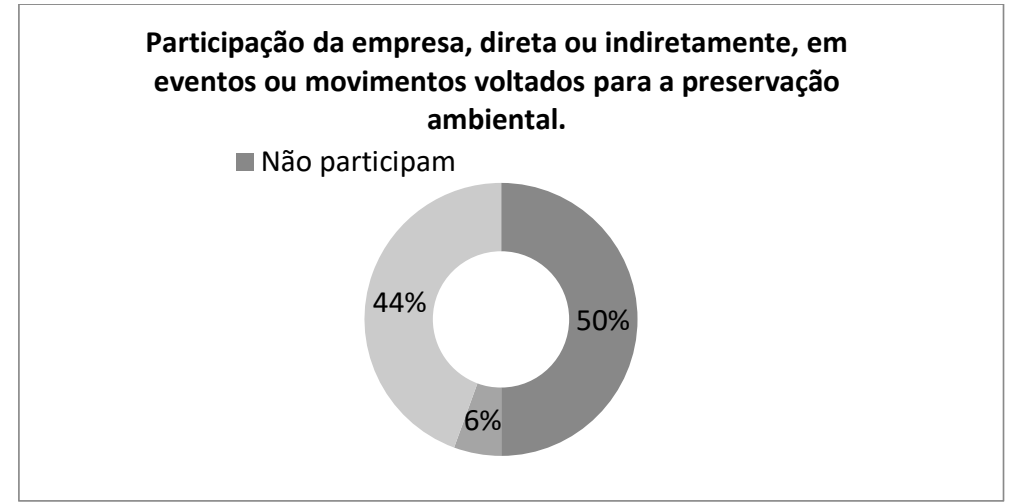

Figura 4: Participação da empresa, direta ou indiretamente, em eventos ou movimentos voltados para a preservação ambiental.

Em se tratando de quais seriam os fatores motivadores para a adoção de boas práticas ambientais no estabelecimento: 5,6\% não utiliza nenhuma prática ambiental; compõem os $88,8 \%$ fatores concernentes a hábitos culturais, preservação e organização do meio ambiente, responsabilidade ambiental, evitar o aquecimento global e a transmissão de doenças, sustentabilidade, a limpeza e a sensação de bem-estar na oficina, outros já trabalharam em empresas que investiam na área ambiental. Outros fatores ainda citados enquadram-se em evitar a poluição do meio ambiente, trabalhar em um ambiente limpo, a redução nas faturas de consumo de água e energia. 5,6\% não responderam. Por conseguinte, verifica-se que esses fatores motivadores atuam como propulsor para a aplicação de boas práticas ambientais.

No que tange aos tipos de resíduos gerados nas oficinas, 11,1\% não responderam e as respostas inseridas nos 88,9\% foram: papel, plástico, metal, lixo químico, papelão, borracha, alumínio, restos de óleo diesel, mineral e hidráulico, embalagens contaminadas com óleo, peças sem conservação, filtro de óleo, estopas sujas, bateria usada, pneus e peças usados, sobras de torno (cavaco), latas de thinner e tinta, óleo de motor e de câmbio, peças usadas, buchas, peças de metal e de plástico, resíduo de carbureto. Com esse demonstrativo, nota-se a geração de resíduos pertencentes às classes I (Perigosos), como o óleo usado ou contaminado, o thinner e as tintas usadas nas pinturas dos veículos, tais resíduos, de acordo com a norma ABNT NBR 10004 (BRASIL, 2004), apresentam característica de toxicidade. O resíduo de carbureto de cálcio, segundo sua Ficha de Informações de Segurança de Produtos Químicos (FISPQ no: W-0002-E), “não deve 
entrar em contato com a umidade, pois o produto pode liberar gases inflamáveis e o material resultante passa a ter um pH básico podendo causar queimaduras por contato" (MARTINS, 2017). Papéis, papelões e embalagens plásticas quando não contaminadas por óleo, podem ser destinadas à reciclagem, portanto enquadram-se como resíduos classe II (não-perigosos). Os metais podem ser destinados à empresas que também façam a reciclagem da sucata, os frascos de óleo, baterias e pneus usados devem estar inseridos na logística reversa.

No que concerne à qual destinação ou tratamento mais adequado para os resíduos gerados na oficina, $11,1 \%$ não responderam; $5,6 \%$ entendem que manter o ambiente limpo e organizado é o tratamento mais adequado; $16,6 \%$ associam a acondicionar os resíduos e o caminhão da coleta recolher; $11,1 \%$ reutilizam o óleo e as peças usadas são acondicionadas para que o caminhão da coleta recolha. 55,6\% compreendem aqueles que destinam os resíduos de forma mais correta, isto é, afirmaram que há uma pessoa que passa recolhendo a sucata metálica, as baterias são devolvidas ao fabricante, pneus usados são armazenados, o resíduo de carbureto é usado para fazer adubo, o óleo usado é armazenado para outros fins, outro respondente apenas citou os procedimentos que devem ser seguidos para destinação adequada dos resíduos. No entanto, esses respondentes redigiram que alguns resíduos são levados pelo caminhão da coleta, até mesmo estopas sujas de óleo. Como é possível observar, a maioria dos proprietários das oficinas entende que os resíduos resultantes de suas atividades precisam ser destinados de forma adequada e que o destino final dado pela rede pública de coleta do município não é o correto. Entretanto, na medida do possível e mais acessível, alguns resíduos passíveis de reciclagem ou reutilização são assim destinados.

No tocante à empresa possuir Sistema de Gestão Ambiental (SGA), 5,6\% respondeu que sim; 5,6\% não respondeu e $88,8 \%$ responderam que não (Figura 5). A implantação de um Sistema de Gestão Ambiental proporcionaria diversos benefícios às oficinas e ao meio ambiente. Porém, não se trata de um processo simples, este contexto pode ser entendido a partir da definição proposta por Santos et al. (2015), os quais conceituam SGA como um conjunto de atividades interagentes que trata dos problemas ambientais, minimizando ou evitando seu surgimento. O SGA requer a formulação de diretrizes, planos, metas, objetivos e a execução e coordenação de atividades, mensuração e avaliação de resultados, por meio de procedimentos escritos e formais. Os propósitos centrais direcionam ao estabelecimento de políticas/procedimentos que favoreçam a organização a atingir os objetivos ambientais anteriormente traçados e administrar riscos ambientais vulneráveis à atividade empresarial.

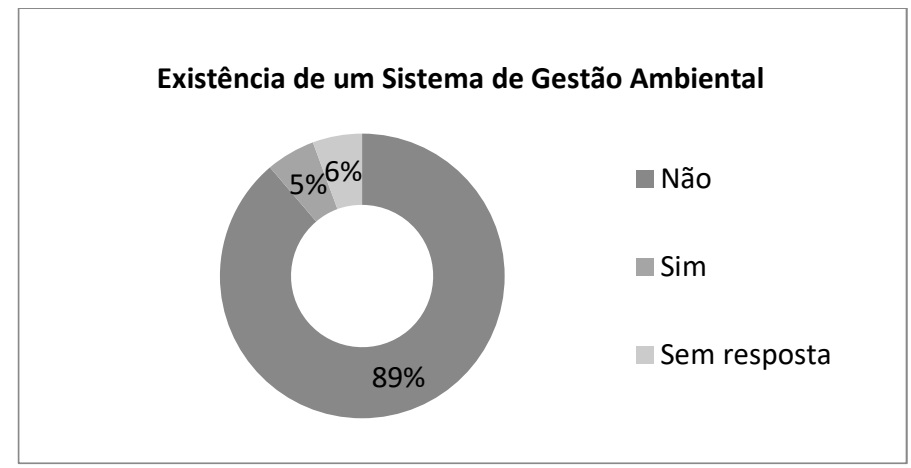

Figura 5: Existência de um Sistema de Gestão Ambiental. 


\section{CONCLUSÕES}

A partir do que foi explanado, entende-se que a responsabilidade ambiental não pode ser pautada apenas na aplicação de ações que tenham grandes repercussões. A utilização de práticas ambientais ainda que exíguas, podem agregar mudanças nos hábitos dos funcionários da empresa e, consequentemente, melhorias para o meio ambiente. Esse comportamento limitado a atitudes que favoreçam apenas a manutenção de limpeza e organização do ambiente de trabalho, provavelmente se justifica pelo fato de os responsáveis pelos estabelecimentos apresentarem pouco conhecimento sobre a legislação ambiental, como foi constatado.

Nesse contexto foi identificado que as oficinas não possuem estratégias de gestão ambiental inseridas em seu planejamento organizacional, por outro lado, notou-se o compromisso quanto às práticas já aplicadas, apesar de ainda não serem suficientes para atender ao disposto na legislação vigente. Ainda assim é importante destacar que, como todo processo acontece de forma gradual, para a aplicação contínua de práticas ambientais nas oficinas, é necessário campanhas de educação ambiental específicas; capacitação dos funcionários para orientá-los quanto aos procedimentos de segregação dos resíduos; fiscalização periódica; incentivos por parte do município que atuem como estratégia motivacional; ademais, é importante a atuação daqueles que trabalham com o transporte e destinação dos resíduos recicláveis.

\section{REFERÊNCIAS}

ABNT. Associação Brasileira de Normas Técnicas. NBR

10004: Resíduos Sólidos - classificação. Rio de Janeiro, 2004

ABNT. Associação Brasileira de Normas Técnicas. NBR 10006: Procedimento para obtenção de extrato solubilizado de resíduos sólidos. Rio de Janeiro, 2004.

ABNT. Associação Brasileira de Normas Técnicas. NBR 11174: Dispõe sobre o armazenamento de resíduos classes II - não inertes e III - inertes. Rio de Janeiro: 1990.

ABNT. Associação Brasileira de Normas Técnicas. NBR 12235: Armazenamento de resíduos sólidos perigosos. Rio de Janeiro, 1992.

ABRELPE. Associação Brasileira de Empresas de Limpeza Pública e Resíduos Especiais. Panorama dos resíduos sólidos no Brasil. São Paulo, 2017.

ALMEIDA, F. A.. O bom negócio da sustentabilidade. 1 ed. Lisboa: Nova Fronteira, 2002.

BARRETTO, L.. Poucas empresas acreditam em retorno financeiro gerado pela sustentabilidade. SEBRAE. Portal Brasil. Meio Ambiente. 2012.

BELFI, T. G.; LIMA, M. C.; MILAGRES, P. F.; ASSIS, N. F. S.; CASTILHO, R. A. A.. Projeto de regularização e adequação ambiental de oficinas mecânicas. In: CONGRESSO BRASILEIRO DE GESTÃO AMBIENTAL, 5. Anais. Belo Horizonte: IBEAS, 2014.

BERNARDO; J. S. S.; CAMAROTTO, J. A.. Fatores motivadores da adoção de práticas ambientais em empresas paulistas processadoras de madeira. Production, São Carlos, v.22, n.1, p.173-184, 2012.

BRASIL. Resolução n.001: Dispõe sobre critérios básicos e diretrizes gerais para a avaliação de impacto ambiental. Conselho Nacional do Meio Ambiente (Brasil). Resoluções do Conama: Resoluções vigentes publicadas entre setembro de 1984 e janeiro de 2012. Brasília: MMA, 2012.

BRASIL. Resolução n.237: Dispõe sobre a revisão e complementação dos procedimentos e critérios utilizados para o licenciamento ambiental. Conselho Nacional do Meio Ambiente (Brasil). Resoluções do Conama: Resoluções vigentes publicadas entre setembro de 1984 e janeiro de 2012. Brasília: MMA, 2012.

BRASIL. Resolução n.275: Estabelece o código de cores para os diferentes tipos de resíduos, a ser adotado na identificação de coletores e transportadores, bem como nas campanhas informativas para a coleta seletiva. Conselho Nacional do Meio Ambiente (Brasil). Resoluções do Conama: Resoluções vigentes publicadas entre setembro de $1984 \mathrm{e}$ janeiro de 2012. Brasília: MMA, 2012.

BRASIL. Resolução n.362: Dispõe sobre o recolhimento, coleta e destinação final de óleo lubrificante usado ou contaminado. Conselho Nacional do Meio Ambiente (Brasil). Resoluções do Conama: Resoluções vigentes publicadas entre setembro de 1984 e janeiro de 2012. Brasília: MMA 2012.

BRASIL. Resolução n.416: Dispõe sobre a prevenção à degradação ambiental causada por pneus inservíveis e sua destinação ambientalmente adequada, e dá outras 
providências. Conselho Nacional do Meio Ambiente (Brasil). Resoluções do Conama: Resoluções vigentes publicadas entre setembro de 1984 e janeiro de 2012. Brasília: MMA, 2012.

BRASIL. Constituição de 1988: Capítulo VI: Do Meio Ambiente. Art. 225: Constituição da República Federativa do Brasil. 2016. Brasília, 1988.

BRASIL. Lei n.9.605: Dispõe sobre as sanções penais e administrativas derivadas de condutas e atividades lesivas ao meio ambiente, e dá outras providências. Art. 54, § 2으, inciso V. 2018. Brasília: DOU, 1998.

BRASIL. Lei 12.305: Institui a Política Nacional de Resíduos Sólidos; altera a Lei no 9.605, de 12 de fevereiro de 1998; e dá outras providências. Art. 3o inciso X. Brasília: DOU, 2010.

CAMPOS, H. K. T.. Renda e evolução da geração per capita de resíduos sólidos no Brasil. Eng Sanit Ambient, Brasília, v.17, n.2, p.171-180, 2012.

ECKERT, A.; CORCINI NETO, S. L. H.; BOFF, D. S.. Iniciativas e práticas ambientais das pequenas e médias empresas do Vale do Caí/RS. Revista de Gestão Ambiental e Sustentabilidade/GeAS, São Paulo, v.4, n.1, 2015.

EL TUGOZ, J.; BERTOLINI, G. R. F.; BRANDALISE, L. T.. Captação e aproveitamento da água das chuvas: o caminho para uma escola sustentável. . Revista de Gestão Ambiental e Sustentabilidade/GeAS, São Paulo, v.6, n.1, p.26-39, 2017.

GERHARDT, A. E.; DRUMM, F. C.; GRASSI, P.; FLORES, B. A.; PASSINI, A. C. F.; BORBA, W. F.; KEMERICH, P. D. C. Diagnóstico para o gerenciamento dos resíduos sólidos em oficina mecânica: estudo de caso em concessionária do município de Frederico Westphalen/RS, Revista Monografias Ambientais/REMOA, Santa Maria, v.14, n.1, p.2899-2908, 2014.

GODECKE, M. V.; NAIME, R. H.; FIGUEIREDO, J. A. S.. O consumismo e a geração de resíduos sólidos urbanos no Brasil. Rev. Elet. em Gestão e Tecnologia Ambiental, Cascavel, v.8, n.8, p.1700-1712, 2012.

HEPPER, E. L.; HANSEN, P. B.; SANTOS, J. L. S.. Iniciativas sustentáveis e desempenho organizacional: uma análise das publicações na base Web of Science. Revista de Gestão Ambiental e Sustentabilidade/GeAS, São Paulo, v.5, n.2, p.99-114, 2016
IBGE. Instituto Brasileiro de Geografia e Estatística. Piauí, Corrente. BRASIL, 2010.

ISA. Instituto Socioambiental. Unidades de Conservação no Brasil: PARNA das Nascentes do Rio Parnaíba. Parnaíba, 2017.

JUSTEN C. E.; NETO L. M.. Do economicismo à dialogicidade: as contribuições do paradigma da ecologia profunda e da noção de gestão social para a temática da sustentabilidade empresarial. Cad. EBAPE.BR, Rio de Janeiro, v.10, n.3, p.736750, 2012.

MARTINS, P. S.; FILHO, E. E.; NAGANO, M. S.. Fatores contingenciais da gestão ambiental em pequenas e médias empresas. RAM: Rev. Adm. Mackenzie, São Paulo, v.17, n.2, p.156-179, 2016

MORAIS, D. O. C.; OLIVEIRA, N. Q. S.; SOUZA, E. M.. As práticas de sustentabilidade ambiental e suas influências na nova formatação institucional das organizações. Revista de Gestão Ambiental e Sustentabilidade/GeAS, São Paulo, v.3, n.3, p. 90-106, 2014

QUERINO, L. A. L.; PEREIRA, J. P. G.. Geração de resíduos sólidos: a percepção da população de São Sebastião de Lagoa de Roça, Paraíba. Revista Monografias

Ambientais/REMOA, Santa Maria, v.15, n.1, p.404-415, 2016.

SÁNCHEZ, L. E.. Avaliação de Impacto Ambiental: conceitos e métodos. 2 ed. São Paulo: Oficina de Textos, 2013.

SANTOS, G. S.; SEHNEM, S.; FREITAS, M. S.. Avaliação do nível de sustentabilidade de um curtume gaúcho à luz do sistema de gestão ambiental (SGA). Revista de Gestão Ambiental e Sustentabilidade/GeAS, São Paulo, v.4, n.2, p.102-117, 2015

SEBRAE. Ideias de Negócio: Oficina Mecânica. São Paulo, 2018.

SOUZA, R. S.. 1.9 Fatores de formação das estratégias ambientais empresariais no contexto das empresas. In: Sustentabilidade: Resultados das pesquisas do PPGA/EA/UFRGS. Porto Alegre, 2013.

STEPHANOU, J.. Gestão de resíduos sólidos: um modelo integrado que gera benefícios econômicos, sociais e ambientais. In: Sustentabilidade: Resultados das pesquisas do PPGA/EA/UFRGS. Porto Alegre, 2013.

A CBPC - Companhia Brasileira de Produção Científica (CNPJ: 11.221.422/0001-03) detém os direitos materiais desta publicação. Os direitos referem-se à publicação do trabalho em qualquer parte do mundo, incluindo os direitos às renovações, expansões e disseminações da contribuição, bem como outros direitos subsidiários. Todos os trabalhos publicados eletronicamente poderão posteriormente ser publicados em coletâneas impressas sob coordenação da Sustenere Publishing, da Companhia Brasileira de Produção Científica e seus parceiros autorizados. Os (as) autores (as) preservam os direitos autorais, mas não têm permissão para a publicação da contribuição em outro meio, impresso ou digital, em português ou em tradução. 